๓

(1)

(1)

\title{
Interview with Dr. Kripa Raman: Research Associate at Cornerstone Research Group
}

\author{
By Pedrum Mohammadi-Shemirani
}

Dr. Kripa Raman completed her PhD in Medical Sciences from McMaster University, having written a thesis on the discovery and validation of blood-based RNA markers to differentiate between subtypes of stroke and predict their prognosis. Prior to this, she received a BSc in Molecular Biology and Genetics with a minor in Biochemistry, also from McMaster University. She is currently a research associate at Cornerstone Research Group, a consulting firm in Burlington that specializes in evidence-based market access solutions for pharmaceutical and biotechnology products.

\section{How did your graduate education prepare you for your career?}

My thesis projects involved big data, which required me to deepen my understanding of statistics and introduced me to $\mathrm{R}$, a programming language for statistical computing and graphics. The ability to understand and write code is very valuable in my current position. More generally, my graduate education gave me opportunities to fine-tune my ability to critically evaluate and discuss scientific literature, conduct literature reviews, and to answer complex questions. All of these are skills I use on a regular basis at Cornerstone.

2. What is your average day/week like? Can you describe a current project you are working on?

Each week is different depending on the project requirement. This week I've spent the first few hours of the day catching up on readings. Then I switch to setting up and programming an economic model. Intermittently through the day I meet with managers and/or clients to discuss issues, present progress, and garner feedback.

One of my first projects at Cornerstone was a market scan for a pharmaceutical product. This involved the study and interpretation of events and trends that could influence the market (i.e., disease epidemiology, current management of treatment, emerging competitors, etc.). This big picture view can help a company better understand their customers, and identify competitors' vulnerabilities.

Initially the project was a bit daunting since there was such a wide scope, and it was a new disease area. Actually, it was similar to starting a thesis! This project was also my first exposure to health technology assessment bodies (i.e., Canadian Agency for Drugs and Technologies in Health (CADTH) and the National Institute for heath and Care Excellence (NICE)). These organizations are responsible for evaluating the efficacy and cost effectiveness of new health product. Now I'm working on developing clinical and economic tools to convey the importance of new products to agencies like CADTH.

\section{What is your favourite and least favourite part about the job?}

During my PhD I was surprised how much I enjoyed the data analysis and programming aspect of my research. Luckily, I have had ample opportunities to use these skills in my job, and even to do some new types of programming as well. I also really enjoy collaborating with clients, and the variety in projects.

My least favourite aspect is writing and editing large reports, but it's an important and necessary part of most jobs.

\section{What is the current demand for MSc or PhD students in your field?}

In general, the job market in health economics seems pretty good. The cost of healthcare is a hot topic right now, which makes cost effectiveness and budget impact analyses that much more important for pharmaceutical and biotechnology companies trying to get reimbursement. 


\section{HealTh SCience Inquiry}

In terms of educational background, the majority of my co-workers have graduate degrees (MSc or PhD). The job requires the ability to critically evaluate scientific literature, which is a skill often developed in grad school.

\section{Do you have any advice for current graduate students who would like to envisage a similar career path?}

I would suggest learning more about the role of government and health technology agencies. Reading some of the drug recommendations by CADTH, for example, will help you to become familiar with the clinical evaluations and the economic language. 